\title{
Protective effects of a novel facial cream against environmental pollution: in vivo and in vitro assessment
}

\section{Mridvika Narda \\ Gabriel Bauza \\ Palmira Valderas \\ Corinne Granger}

Innovation and Development, ISDIN SA, Barcelona, Spain
Correspondence: Mridvika Narda Innovation and Development, ISDIN S.A., Provençals 33, Barcelona 08019, Spain $\mathrm{Tel}+34932402020$ extension 1012 Fax +34932020980

Email mridvika.narda@isdin.com
This article was published in the following Dove Press journal: Clinical, Cosmetic and Investigational Dermatology

Background: The effects of pollution on health have received increasing attention in recent years. Extrinsic skin aging occurs via multiple processes, and pollution is now recognized as a major component, causing increased pigmentation and wrinkles via oxidative mechanisms. We tested the antipollution efficacy of a cosmetic facial cream (FC) by assessing its effects on carbon particle adhesion to skin and on oxidative and inflammatory pathways in the skin.

Methods: In an in vivo study, FC was applied once to the forearms of healthy subjects. Carbon E153 powder was applied, and the skin was washed under standardized conditions. Images were taken using a dermoscope to determine the area of particle adherence. Each participant served as their own control, with the contralateral forearm being untreated with the FC but otherwise following the same protocol. In a 5-day ex vivo study, skin explants were treated with the FC daily and exposed to vaporized pollutants on day 2 and day 4 via a closed system. Explants were sampled at baseline and day 5 and culture media on day 5. The parameters evaluated were cellular viability on microscopy, Nrf2 immunostaining, malondialdehyde (MDA) levels in culture, melanin levels, and gene expression profile (TYR, IL6, and CYP1A1).

Results: In the in vivo adhesion study, after standardized washing, carbon particle deposition on skin treated with the FC was significantly lower than that on untreated skin. In the ex vivo study, samples treated with the FC had reduced Nrf2 staining and MDA levels vs polluted controls. Melanin did not change significantly. The FC modulated pollution-induced increases in CYP1A1, IL-6, and TYR.

Conclusion: This FC reduces particle adhesion to skin after a single application and protects against pollution-induced oxidative and inflammatory pathways in the skin.

Keywords: pollution, skin aging, shield, barrier, exopolysaccharide, genomic, Nrf2, TYR

\section{Introduction}

Recent years have witnessed a greater awareness of the damage human activity has wreaked on the environment. More than ever, attention, in both the lay and scientific community, is focused on the role of environmental pollution in various disease conditions. ${ }^{1-3}$ The effect of air pollution on skin, while seeming a logical corollary to skin being the barrier between environment and the body, has only recently begun to be supported by scientific evidence. Pollution has been shown to have multiple deleterious effects on the skin including hyperpigmentation, wrinkles, sallow appearance of the skin, and exacerbation of acne, ${ }^{4}$ skin cancer, ${ }^{5}$ atopic dermatitis, ${ }^{6}$ and psoriasis. ${ }^{7}$ 
The etiology of skin aging is multifactorial with numerous intrinsic and extrinsic factors colluding to produce visible changes in phenotype. Pollution has been recognized as one of the driving factors that accelerate skin aging, besides solar radiation, as proposed by the exposome theory. ${ }^{8}$ Protection of skin from air pollution is considered an essential part of a multipronged approach to slowing skin aging.

Air pollution varies by region and level of rural or industrial activity. However, some of the universal components include polycyclic aromatic hydrocarbons (PAHs), fine and very fine particulate matter $\left(\mathrm{PM}_{2.5}\right.$ and $\left.\mathrm{PM}_{10}\right)$, heavy metals, and gases such as sulfur dioxide, nitrogen oxide, and carbon monoxide. ${ }^{3,7}$ The interaction of one or more of these components with skin results in the generation of reactive oxygen species (ROS) that react with cellular proteins, lipids, and DNA, triggering downstream events. ${ }^{9}$ An inflammatory cycle is triggered, with the release of cytokines, causing inflammatory cell migration and infiltration and further generation of free radicals. ${ }^{7}$ Changes in membrane lipids and proteins damage cell structure and function and, in particular, the skin's barrier function. ${ }^{10}$ Epidermal vitamins $\mathrm{C}$ and $\mathrm{E}-$ nonenzymatic antioxidants - are depleted, ${ }^{11}$ as are multiple enzymatic antioxidants. ${ }^{9}$

Protecting skin against such damage may be approached in two ways: by the formation of a physical barrier on the skin surface to limit pollution contact with the skin and by counteracting the subsequent downstream events - namely oxidative stress. A novel facial cream (FC) was designed to act in both ways against pollution: it contained a film-forming exopolysaccharide (EPS) capable of adsorbing heavy metals and preventing particulate matter adhesion ${ }^{12,13}$ and carnosine and niacinamide to minimize the oxidative and inflammatory downstream effects of pollution. We report the results from an in vivo study to determine the effects of topical application of the cream on inhibiting carbon powder adhesion to healthy skin as well as an ex vivo study to determine the effects of the cream against pollution-induced markers of oxidation and inflammation in skin explants.

\section{Methods}

\section{Particle adhesion study}

\section{Subjects}

Twenty healthy adult female subjects were enrolled (inclusion criteria: $18-70$ years). Individuals who were pregnant, breastfeeding, tattooed on the inner forearms, or recently exposed to sun or psoralen and ultraviolet A (PUVA) therapy were excluded. All subjects provided written informed con- sent. The study was performed in accordance with the 1964 Declaration of Helsinki and its successive updates and the recommendations on Good Clinical Practice ICH E6 (R2) 2016. The study was conducted in France, and as the nature of the study did not fall within the classification of medical research, as described in decree number $2017-884,{ }^{14}$ but rather of a cosmetic product, it did not require ethics committee approval. Prior to the current study, the product had previously undergone safety testing as recommended in the 2008 Colipa guidelines for the evaluation of the efficacy of cosmetic products ${ }^{15}$ and had been determined to be safe for use as a cosmetic product.

\section{Protocol}

A $5 \mathrm{~cm} \times 5 \mathrm{~cm}$ square was marked on both inner forearms, with a smaller $4 \mathrm{~cm} \times 4 \mathrm{~cm}$ square inside this, using a dermographic pencil. Participants were instructed to avoid touching, wetting, or rubbing their forearms throughout the study.

Subjects were randomized to have the FC applied to either the left or right forearm; the arm with no FC applied served as a control. A technician applied $50 \mu \mathrm{L}\left(2 \mu \mathrm{L} / \mathrm{cm}^{2}\right)$ of the cream to the larger square on the treated arm and left it to dry for 15 minutes. Then, the powder of carbon particles (carbon E153 powder [Colorey SAS, Lozanne, France], granulometry diameter [D]: D10: $2 \mu \mathrm{m}$, D50: $5 \mu \mathrm{m}$, D90: $55 \mu \mathrm{m}$ ) was applied to the inner square on both forearms: $4 \mathrm{mg}$ on each arm, using a brush and fingertip. The test areas were rinsed with $30 \mathrm{~mL}$ of water; after that, $75 \mu \mathrm{L}$ of neutral liquid soap was applied and massaged for 30 seconds, and then rinsed under running water for 5 seconds. The skin was dried by placing a tissue on the skin without rubbing.

\section{Imaging}

Images were taken with a C-Cube Dermoscope Clinical Research Edition camera (Pixience SAS, Toulouse, France) before FC application (T0), immediately after the application of carbon E153 powder (T1), and immediately after washing (T2). This camera uses a probe with an embedded high-resolution camera (10-megapixel complementary metal oxide semiconductor sensor) coupled with a patented lighting technique to avoid glare. Images were analyzed with Kalliste imaging software (Microvision, Evry Cedex, France). For each subject, a region of interest was delimited on the photograph. To establish the surface area covered with carbon E153 powder, the photograph was processed using adaptive thresholding to convert the image to a binary image of clean vs carbon-covered skin. 


\section{Statistical analyses}

Results are shown as mean \pm SD. For each area - treated and control - the efficacy coefficient was calculated according to the following formula: ([T2-T0]-[T1-T0])/(T1-T0). The Shapiro-Wilk test was used to assess the normality of distribution (1\%), which confirmed normal distribution; therefore, the Student's $t$-test was used. A $P$-value of $<0.05$ was considered statistically significant.

\section{Ex vivo study}

\section{Experimental groups}

Human skin explants were obtained from subjects undergoing esthetic surgery in accordance with French Law number 2011814 of July 7, 2011, on bioethics. ${ }^{16}$ Skin was cut into $14 \mathrm{~mm}$ disks and maintained in survival medium at $37^{\circ} \mathrm{C}$ in a humid $5 \% \mathrm{CO}_{2}$ atmosphere. There were four experimental groups, each containing seven explants, which are given in Table 1.

\section{Pollution exposure and FC application}

The FC was applied on days $0,1,2,3,4$, and 5 with a small spatula $\left(2 \mu \mathrm{L} / \mathrm{cm}^{2}\right)$. Explants were exposed to pollution on days 2 and 4, in a closed system that exposes the stratum corneum to vaporized solution introduced using a nebulizer. The explants were placed in $900 \mu \mathrm{L} /$ well of Hanks' balanced salt solution (HBSS), exposed to the pollutants for 1.5 hours, and then returned to the incubator.

The pollutant mixture used was composed of diesel particles $\left(\mathrm{PM}_{2.5}\right.$ and $\left.\mathrm{PM}_{10}\right) 0.01 \%$, benzene $1 \mu \mathrm{L} / \mathrm{mL}$, benzo[a] pyrene $1 \mathrm{mg} / \mathrm{mL}$, and heavy metals (National Institute of Standards and Technology standard reference material, 1650b). The pollutant concentration in the chamber was chosen to be reflective of the levels found in a polluted city.

\section{Sampling}

At day 0 and day 5 , three explants from each group were cut into three parts each: one was fixed in buffered formalin,

Table I Experimental groups in the antipollution activity: ex vivo study

\begin{tabular}{|l|l|l|}
\hline $\begin{array}{l}\text { Group } \\
\text { code }\end{array}$ & $\begin{array}{l}\text { Exposed to } \\
\text { pollution? }\end{array}$ & $\begin{array}{l}\text { Treated } \\
\text { with FC? }\end{array}$ \\
\hline UC & No & No \\
\hline FCC & No & Yes \\
\hline PC & Yes & No \\
\hline FCP & Yes & Yes \\
\hline
\end{tabular}

Abbreviations: $\mathrm{FC}$, facial cream; FCC, FC-treated control; FCP, FC-treated and exposed to pollution; PC, pollution control; UC, untreated control. one was frozen at $-80^{\circ} \mathrm{C}$, and one was used to extract RNA for subsequent genomic study. A further three explants from each group were frozen for subsequent melanin quantification. Culture medium was harvested on day 5 and stored at $-20^{\circ} \mathrm{C}$ for malondialdehyde (MDA) quantification.

\section{Histological processing}

Skin samples were fixed in buffered formalin, dehydrated, and impregnated in paraffin using a Leica PEARL dehydration automat and Leica EG1160 embedding station (Leica Microsystems, Wetzlar, Germany). Five-micrometer sections were cut with a Leica RM2125 Minot microtome. Frozen samples were cut into $7 \mu \mathrm{m}$-thick sections using a Leica CM 3050 cryostat. Sections were then mounted on Superfrost plus silanized glass slides, and a Leica DMLB or Olympus BX43 microscope was used for viewing. Pictures were digitized with a numeric DP72 Olympus camera with CellD storing software.

\section{Skin viability}

Paraffinized sections were stained with Masson's trichrome (Goldner variant) to assess general morphology and skin viability.

\section{Nuclear factor (erythroid-derived 2)-like 2 (Nrf2) immunostaining}

Nrf2 immunostaining was conducted on deparaffinized sections using a monoclonal anti-Nrf2 (phospho S40) antibody (reference ab76026, clone EP1809Y; Abcam, Cambridge, UK) diluted at 1:200 in 0.3\% BSA in PBS and $0.05 \%$ Tween 20 . The antibody is specific for the serine- 40 phosphorylated nuclear form of Nrf2. Sections were incubated for 1 hour at room temperature with an avidin-biotin amplifier system and revealed using a peroxidase kit (ref. SK-4600; Vector laboratories, Burlingame, CA, USA). Sections were evaluated by a histopathologist, and the level of staining was categorized as follows: very weak, weak, moderate, quite clear, clear, very clear, or strong.

\section{MDA}

MDA in culture medium on day 5 was measured for the four explants per batch with an enhanced thiobarbituric acid reagent (TBAR) method. MDA was assayed in HBSS medium with the addition of TBAR solution (thiobarbituric acid, hydrochloric acid, and trichloroacetic acid) and placed in a water bath at $80^{\circ} \mathrm{C}$ for 15 minutes followed by a liquid/ liquid extraction of MDA with butanol. MDA was measured by spectrofluorimetry using a Tecan Infinite M200 Pro 
microplate reader (excitation: $515 \mathrm{~nm}$, emission: $550 \mathrm{~nm}$; Tecan Group Ltd., Männedorf, Switzerland).

\section{Melanin quantification}

Epidermal melanin levels were determined using the method described previously by Costin and Raab. ${ }^{17}$ Briefly, skin samples were incubated in $1 \mathrm{~N}$ sodium hydroxide solution for 1 hour at $80^{\circ} \mathrm{C}$. The quantity of melanin in $\mathrm{NaOH}$ of each sample was measured by absorbance at $330 \mathrm{~nm}$ using an Infinite M200 Pro microplate reader (Tecan Group Ltd.).

\section{RNA extraction and evaluation}

Tissue was disrupted and homogenized and total RNA was extracted using the ReliaPrep RNA Tissue Miniprep System for fibrous tissue (Promega Corporation, Fitchburg, WI, USA). The RNA was purified with DNase digestion and quantified using BioDrop spectrophotometer (BioDrop, Cambridge, UK) and evaluated for quality by capillary electrophoresis with Experion (Bio-Rad, Irvine, CA, USA).

\section{Reverse transcription of RNA and quantitative PCR (qPCR)}

To generate cDNA, $100 \mathrm{ng}$ of each RNA sample was reverse transcribed using the iScript kit (Bio-Rad). For qPCR reactions, cDNA was diluted 1/10 in RNase/DNase-free water and amplified with primer pairs for the tested genes and two housekeeping genes, GAPDH and B2M. Three samples were generated, and repeated experiments were performed on all cDNAs, such that each test condition was sampled six times. Appropriate controls were included to discount nonspecific signal generated by amplification of contaminating DNA fragments. For quantification of all genes, the number of cycles was normalized to the reference gene (GAPDH or B2M) and different treatments were evaluated by comparison with the control values on day 5 . A fold change of $\geq 1.45$ or $\leq 0.6$ was considered upregulated or repressed, respectively.

\section{Results}

\section{Particle adhesion in vivo study}

\section{Subjects}

Twenty-three subjects were enrolled; three were excluded because the images could not be assessed, leaving 20 subjects in the final analysis. Subject characteristics are summarized in Table 2.

\section{Carbon EI53 powder adhesion}

The mean $( \pm \mathrm{SD})$ areas of skin with carbon E153 powder deposition at baseline were $0.178( \pm 0.222)$ and $0.141( \pm 0.246)$ $\mathrm{mm}^{2}$ in the FC-treated and control areas, respectively. At T1 (immediately after the application of carbon E153 powder), these areas were $59.039( \pm 7.120)$ and $61.114( \pm 5.474) \mathrm{mm}^{2}$, and at T2 (immediately after washing), they were 3.978 $( \pm 3.937) \mathrm{mm}^{2}$ and $8.532( \pm 6.176)$ (Table 3$)$.

Thus, the efficacy coefficient, that is, the reduction in the area with carbon particle deposition following washing, was $-0.931( \pm 0.073 ; 95 \% \mathrm{CI}-0.963$ to -0.899$)$ in the treated area and $-0.862( \pm 0.098 ; 95 \% \mathrm{CI}-0.908$ to -0.816$)$ in the control area. This represented a $93.1 \%$ reduction in carbon E153 powder deposition in the treated area vs only $86.2 \%$ on untreated skin under the same conditions of cleansing. Thus, the application of FC resulted in a statistically significant $(P=0.004)$ reduction in carbon E153 powder adherence to skin.

\section{Ex vivo study}

\section{Tissue viability}

Figure 1 shows the histological images of skin tissue showing general morphology at baseline and day 5 . There were no appreciable changes in general morphology in any of the treatment groups during the course of the study, suggesting that skin explants were viable throughout the study.

Table 2 Characteristics of the study subjects

\begin{tabular}{|l|l|l|}
\hline No. of patients & \multicolumn{2}{|l|}{20} \\
\hline Sex, female & $20(100 \%)$ \\
\hline Age, years & $40(26-60)$ & I (5\%) \\
\hline \multirow{3}{*}{ Phototype } & I & $9(45 \%)$ \\
\cline { 2 - 3 } & II & $9(45 \%)$ \\
\cline { 2 - 3 } & III & I (5\%) \\
\cline { 2 - 3 } & IV & $20(100 \%)$ \\
\hline Skin type (forearm) & Normal & \\
\hline
\end{tabular}

Table 3 Areas of skin with carbon El53 powder adhesion (mean [SD])

\begin{tabular}{|l|l|l|l|}
\hline \multirow{3}{*}{ Groups } & \multicolumn{3}{|l|}{$\begin{array}{l}\text { Area of skin with carbon } \\
\text { EI53 powder adhesion, } \mathbf{~ m m}^{\mathbf{2}}\end{array}$} \\
\cline { 2 - 4 } & T0 & T I & T2 \\
\hline FC treated & $0.178(0.222)$ & $59.039(7.120)$ & $3.978(3.937)^{\mathrm{a}}$ \\
\hline Control & $0.141(0.246)$ & $61.114(5.474)$ & $8.532(6.176)$ \\
\hline
\end{tabular}

Notes: T0, before FC application; TI, immediately after powder application; T2, immediately after washing. ${ }^{a}=0.004$ on Student's $t$-test for FC-treated vs control groups.

Abbreviation: FC, facial cream. 
A

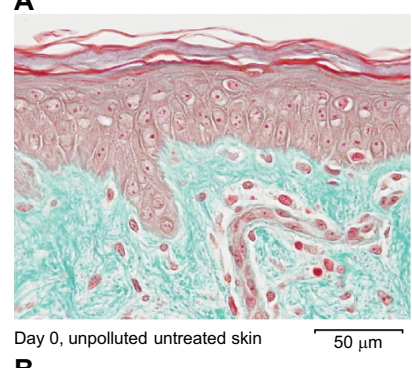

B

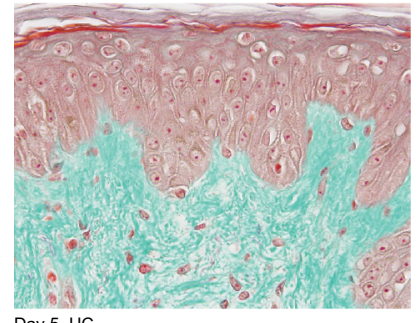

Day 5 , UC

D

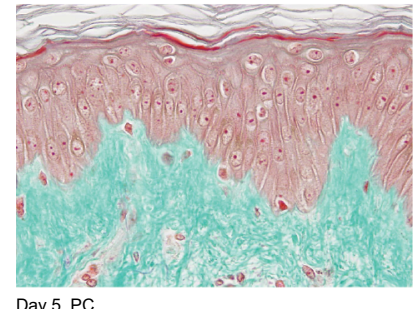

Day $5, \mathrm{PC}$

Figure I Viability study: general morphology at day 0 and day 5 in all sample groups. Abbreviations: FCC, facial cream-treated control; FCP, facial cream-treated and exposed to pollution; PC, pollution control; UC, untreated control.

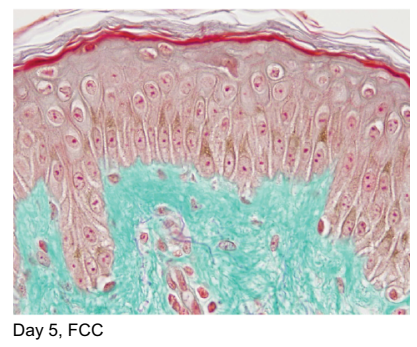

E

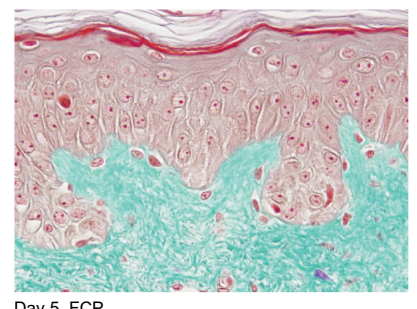

\section{Nrf2 immunostaining}

Day 0 skin sections showed clear staining of $\mathrm{Nrf} 2$ in the living epidermis. At day 5, FC application led to a decrease in the level of staining compared to the control group. Exposure to pollution led to an increase in the level of staining for Nrf2. However, the group with FC application prior to pollution exposure showed levels of staining that were similar to the control group (Figures 2 and 3).

MDA

Mean MDA concentrations in survival culture medium on day 5 for all groups are presented in Table 4. Exposure of skin to pollution for 4 days led to a statistically significant increase of $38 \%$ in MDA concentrations in the culture media (108.5 vs 149 $\mathrm{nmol} / \mathrm{L}$ in untreated control $[\mathrm{UC}]$ and pollution-exposed control [PC] groups, respectively, $P<0.01)$. Topical application of the FC produced a nonsignificant reduction in MDA concentration in the PC group ( $7 \%$ decrease). MDA levels were significantly lower in the FC-treated and exposed to pollution (FCP) group compared to the PC group ( $27 \%$ decrease, $P<0.01)$.

\section{Melanin}

Melanin levels in the different treatment groups are reported in Table 5. There were no statistically significant differences in the values among groups $(P>0.05)$.

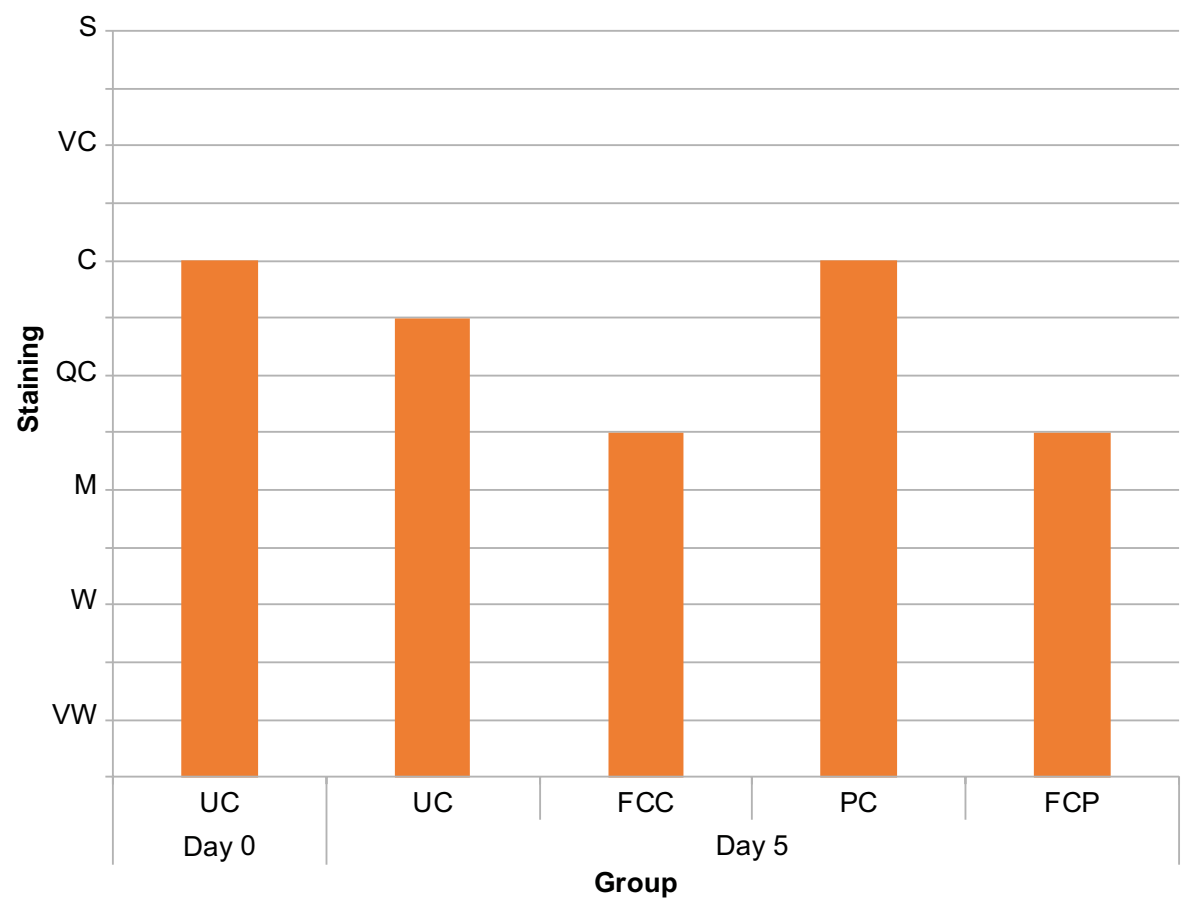

Figure $2 \mathrm{Nrf} 2$ immunostaining levels at day 0 and day 5 in living epidermis.

Abbreviations: C, clear; FCC, facial cream-treated control; FCP, facial cream-treated and exposed to pollution; M, moderate; PC, pollution control; QC, quite clear; S, strong; UC, untreated control; VC, very clear; VW, very weak; W, weak. 
A
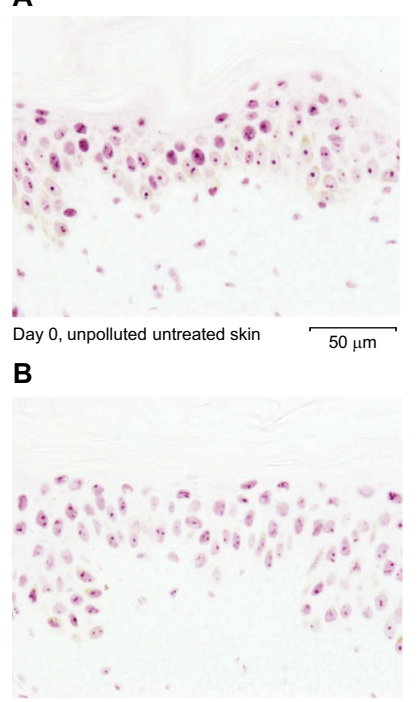

Day 5, UC

D

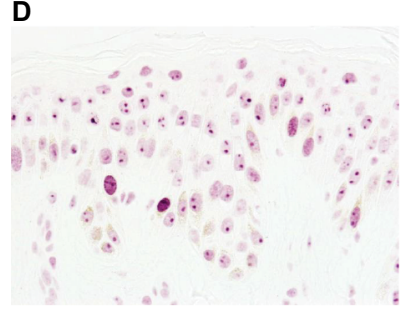

Day 5, PC

\section{C}

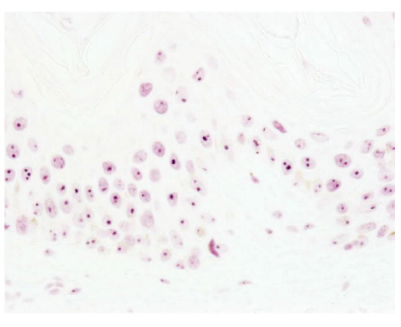

Day 5, FCC

E

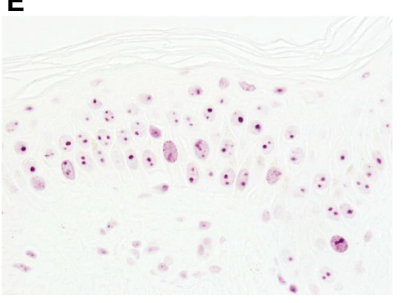

Day 5, FCP

Figure $3 \mathrm{Nrf2}$ immunostaining at day 0 and day 5 in all sample groups. Abbreviations: FCC, facial cream-treated control; FCP, facial cream-treated and exposed to pollution; PC, pollution control; UC, untreated control.

Table 4 MDA levels in culture medium at day 5 (mean [SD])

\begin{tabular}{|l|l|}
\hline Treatment groups & MDA (nmol/L) \\
\hline UC & $108.5(16.9)$ \\
\hline FCC & $100.3(16.0)$ \\
\hline PC & $149.1(9.2)$ \\
\hline FCP & $109.2(7.4)$ \\
\hline
\end{tabular}

Abbreviations: FCC, facial cream-treated control; FCP, facial cream-treated and exposed to pollution; MDA, malondialdehyde; PC, pollution control; UC, untreated control.

Table 5 Epidermal melanin levels at day 0 and day 5 (mean [SD])

\begin{tabular}{|l|l|l|}
\hline & Treatment group & $\boldsymbol{\mu g} / \mathbf{m g}$ of epidermis \\
\hline Day 0 & UC & $3.4(0.9)$ \\
\hline Day 5 & UC & $3.5(0.2)$ \\
\cline { 2 - 3 } & FCC & $3.5(0.2)$ \\
\cline { 2 - 3 } & PC & $2.5(1.1)$ \\
\cline { 2 - 3 } & FCP & $3.2(0.4)$ \\
\hline
\end{tabular}

Abbreviations: FCC, facial cream-treated control; FCP, facial cream-treated and exposed to pollution; PC, pollution control; UC, untreated control.

\section{Gene expression}

Application of the FC to skin did not in itself lead to the upregulation or downregulation of the genes studied. Exposure to pollution led to a change in the expression of three

Table 6 Gene expression at day 5 of ex vivo antipollution activity study

\begin{tabular}{|l|l|l|l|}
\hline \multicolumn{4}{|l|}{$\begin{array}{l}\text { Fold change in gene expression relative } \\
\text { to } \mathbf{U C}^{\mathbf{a}}\end{array}$} \\
\hline Genes & Sample group & \multicolumn{2}{l|}{} \\
\hline & FCC & PC & FCP \\
\hline CYPIAI & 0.93 & 5.74 & 2.22 \\
\hline IL6 & 0.99 & $\mathrm{I} .83$ & $\mathrm{I} .34$ \\
\hline TYR & 0.85 & 1.53 & 0.96 \\
\hline
\end{tabular}

Note: ${ }^{2}$ Fold change of $\geq 1.45$ was considered upregulation and $\leq 0.6$ was considered repression.

Abbreviations: FCC, facial cream-treated control; FCP, facial cream-treated and exposed to pollution; PC, pollution control; UC, untreated control.

genes in skin explants, and the FC modulated this expression (Table 6).

CYP1A1: in the PC group, exposure to pollution led to a 5.74-fold increase in CYP1Al expression compared to the UC group. In the FCP group, this overexpression was limited to 2.22-fold. IL6: in the PC group, exposure to pollution led to a 1.83-fold increase in IL6 expression; in the FCP group, this overexpression was limited to 1.34 -fold ( $<1.45$ fold, hence not considered upregulated). TYR: in the PC group, exposure to pollution led to a 1.53 -fold increase in TYR expression compared to the FCP group, where this gene was not overexpressed.

\section{Discussion}

We present in this study two levels of evidence for the protective effects of topical application of a novel FC against pollution. In vivo, the application of the FC resulted in a statistically significant decrease in the adherence of carbon E153 powder to the skin after washing compared to nude skin (control area). At the cellular level, exposure to pollution led to changes indicative of increased oxidative stress, inflammation, and pigmentation: increased staining for the active form of Nrf2, increased MDA levels in culture medium, and upregulation of CYP1A1, IL6, and TYR genes in human skin explants. Prior application of the FC was able to block to a certain degree all of these changes induced in the skin by exposure to pollution. These results are consistent with certain key ingredients of the FC, which were included to minimize fine particle adhesion to skin and control oxidation and inflammation to ameliorate the downstream effects of such exposure.

In our study, the pollution-induced increase in MDA concentration and in the active form of $\mathrm{Nrf} 2$ indicates oxidative stress,$^{18}$ which is reported in the literature to be the principle deleterious action of pollution on skin. ${ }^{19,20}$ The reduction 
in MDA levels and staining for the active nuclear form of $\mathrm{Nrf} 2$ in the skin explants pretreated with FC demonstrates the protective effect against the cellular changes induced by pollution. This can partly be explained by the presence of niacinamide which has a known anti-inflammatory action ${ }^{21}$ and both niacinamide and carnosine with known antioxidant ${ }^{22}$ action in the skin. Pollution also induced upregulation of IL 6 and $C Y P 1 A 1$ suggesting an inflammatory response to oxidative injury ${ }^{23,24}$ and a protective effect of the FC as seen by the modulation of this response with its application. IL-6 plays a key role in local and systemic inflammation, and CYP1A1 codes for a CYP/CYP450-related detoxification enzyme whose expression is induced by some PAHs, a component of urban pollution. ${ }^{25}$

Other authors have described the effects of pollution on pigment spot formation in the skin. ${ }^{26}$ In our study, after only two periods of exposure to pollution, we observed an upregulation of the TYR gene, which codes for tyrosinase, a key enzyme in melanogenesis. ${ }^{27}$ We did not observe an increase in melanin content in pollution-exposed skin. This may be due to the short duration of the study (5 days) that was not long enough to see changes in melanin levels and represents a potential area for future investigation. The finding that TYR was upregulated by pollution and modulated by the FC suggests an antipollution protective effect of the product.

A film-forming EPS called as alteromonas ferment extract was included in the formulation for its anti-adhesion effect. Previous in vitro and clinical studies showed that a product containing the same EPS, in skin exposed to heavy metals, hydrocarbons, and particulate matter, significantly reduced particle adhesion to skin and protected keratinocyte membranes from lipid peroxidation, preserved cell integrity, and normalized the collagen network. ${ }^{12,13}$

\section{Strengths and limitations}

The strength of this study is that under controlled, standardized, replicable conditions, we provided two levels of evidence on the protective effect of this FC against pollution. The exposure of skin explants to vaporized pollution particles in a closed environment was chosen to be a close approximation of real-life conditions, although ozone, a known component of air pollution, was not included, a point that may be considered a limitation. Other limitations include the absence of a placebo control group and unblinded nature of the clinical study, although a standardized method of powder application and washing was used to minimize interindividual and intergroup variability. The particle adhesion study was conducted on forearm skin, which differs from facial skin, the main target of pollution effects, in characteristics such as density of sebocytes present. The forearm area was chosen for the ease of assessment and the lower risk of inadvertent introduction of carbon particles to the subjects' eyes or upper airways. However, this is a drawback of the in vivo study as facial sebum might affect the adhesion of carbon particles on the skin. A study on facial skin would provide more directly-applicable results. In the clinical study, we report a statistically significant decrease in particle binding in treated skin, yet this study does not allow us to establish a clinical cutoff value beyond which particle binding is known to induce or not skin aging as this is clearly complex and was not the aim of this study. However, when taken together with results from the ex vivo study, clearly this level of mitigation of adhesion of particles has a relevant benefit in terms of markers of oxidative stress.

Increasing understanding of the effects of pollution on skin health suggests that protecting skin against pollution should be a key area of improvement of skincare and antiaging regimens. The effects of ultraviolet exposure on skin aging have been well documented, and applying sun protection is now a standard recommendation in antiaging skincare. As understanding and awareness of the effects of pollution on skin continue to increase, everyday-use products that provide this protection are of increasing relevance especially in highly polluted urban or industrial nuclei.

\section{Conclusion}

Application of FC containing an EPS, carnosine, and niacinamide prior to exposure to carbon particles significantly decreased particle adherence to skin in human subjects. In human skin explants, exposure to urban dust led to an increase in indicators of oxidative stress, while the daily application of the cream over 5 days had a protective effect against pollution-induced changes. These results suggest that this novel FC can help to reduce the harmful oxidative effects of pollution on skin.

\section{Acknowledgment}

J. Marshall provided medical writing assistance in drafting the manuscript.

\section{Disclosure}

MN, GB, PV, and CG are employees of ISDIN S.A, the manufacturer of the cosmetic product tested in this study. The authors report no other conflicts of interest in this work. 


\section{References}

1. Pilz V, Wolf K, Breitner S, et al. C-reactive protein (CRP) and longterm air pollution with a focus on ultrafine particles. Int J Hyg Environ Health. 2018;221(3):510-518.

2. Phung V, Ueda K, Kasaoka S, et al. Acute Effects of Ambient $\mathrm{PM}_{2.5}$ on All-Cause and Cause-Specific Emergency Ambulance Dispatches in Japan. Int J Environ Res Public Health. 2018;15(2):307.

3. WHO [homepage on the Internet]. Air Quality Guidelines for Particulate Matter, Ozone, Nitrogen Dioxide and Sulfur Dioxide, Global Update 2005. Summary of Risk Assessment. 2006. Available from: http://www. who.int/phe/health_topics/outdoorair/outdoorair_aqg/en/. Accessed September 18, 2018.

4. Krutmann J, Moyal D, Liu W, et al. Pollution and acne: is there a link? Clin Cosmet Investig Dermatol. 2017;10:199-204.

5. Baudouin C, Charveron M, Tarroux R, Gall Y. Environmental pollutants and skin cancer. Cell Biol Toxicol. 2002;18(5):341-348.

6. Kim J, Kim EH, Oh I, et al. Symptoms of atopic dermatitis are influenced by outdoor air pollution. J Allergy Clin Immunol. 2013;132(2):495-498.

7. Puri P, Nandar SK, Kathuria S, Ramesh V. Effects of air pollution on the skin: A review. Indian J Dermatol Venereol Leprol. 2017;83(4):415-423.

8. Krutmann J, Bouloc A, Sore G, Bernard BA, Passeron T. The skin aging exposome. J Dermatol Sci. 2017;85(3):152-161.

9. Halliwell B, Cross CE. Oxygen-derived species: their relation to human disease and environmental stress. Environ Health Perspect. 1994;102(Suppl 10):5-12.

10. Baroni A, Buommino E, de Gregorio V, Ruocco E, Ruocco V, Wolf R. Structure and function of the epidermis related to barrier properties. Clin Dermatol. 2012;30(3):257-262.

11. Thiele JJ, Traber MG, Tsang K, Cross CE, Packer L. In vivo exposure to ozone depletes vitamins $\mathrm{C}$ and $\mathrm{E}$ and induces lipid peroxidation in epidermal layers of murine skin. Free Radic Biol Med. 1997;23(3):385-391.

12. Borel M, Lamarque E, Loing E. Unique natural exopolysaccharides for biomimetic protective effect against urban pollution. J Cosmet Sci. 2017;68(1):126-132.

13. Zhang Z, Cai R, Zhang W, Fu Y, Jiao N. A Novel Exopolysaccharide with Metal Adsorption Capacity Produced by a Marine Bacterium Alteromonas sp. JL2810. Mar Drugs. 2017;15(6):175.

14. Decree no 2017-884 of 9 May 2017. Journal Officiel de la Republique Française (JORF). Available from: https://www.legifrance.gouv.fr/ jo_pdf.do?id=JORFTEXT000034634217. Accessed July 10, 2018.
15. Colipa, The European Cosmetics Association. Guidelines for the evaluation of the efficacy of cosmetic products; 2008. Available from: https:// www.cosmeticseurope.eu/files/4214/6407/6830/Guidelines_for_the Evaluation_of_the_Efficacy_of_Cosmetic_Products_-_2008.pdf..

16. Law no. 2011-814 of 7 July onbioethics (article 18). JORF No. 0157 of 8 July 2011 page 11826 text no. 1 NOR: ETSX1117652L. Available from: https://www.legifrance.gouv.fr/affichTexte.do?cidTexte=JORFT EXT000024323102\&dateTexte=20180508. Accessed July 10, 2018.

17. Costin G, Raab H. Optimized In Vitro Pigmentation Screening Assay Using A Reconstructed Three Dimensional Human Skin Model. Rom J Biochem. 2013;50(1):15-27.

18. Osburn WO, Kensler TW. Nrf2 signaling: an adaptive response pathway for protection against environmental toxic insults. Mutat Res. 2008;659(1-2):31-39.

19. Valacchi G, Sticozzi C, Pecorelli A, Cervellati F, Cervellati C, Maioli E. Cutaneous responses to environmental stressors. Ann N Y Acad Sci. 2012;1271:75-81.

20. Vierkötter A, Schikowski T, Ranft U, et al. Airborne particle exposure and extrinsic skin aging. J Invest Dermatol. 2010;130(12):2719-2726.

21. Gehring W. Nicotinic acid/niacinamide and the skin. JCosmet Dermatol. 2004;3(2):88-93.

22. Quinn PJ, Boldyrev AA, Formazuyk VE. Carnosine: its properties, functions and potential therapeutic applications. Mol Aspects Med. 1992;13(5):379-444.

23. Paquet P, Piérard GE. Interleukin-6 and the skin. Int Arch Allergy Immunol. 1996;109(4):308-317.

24. Shimada T, Fujii-Kuriyama Y. Metabolic activation of polycyclic aromatic hydrocarbons to carcinogens by cytochromes P450 1A1 and 1B1. Cancer Sci. 2004;95(1):1-6.

25. Gene [Internet]. Bethesda (MD): National Library of Medicine (US), National Center for Biotechnology Information; 2018. Available from: https:/www.ncbi.nlm.nih.gov/gene/1543. Accessed 10 May, 2018.

26. Hüls A, Vierkötter A, Gao W, et al. Traffic-related air pollution contributes to development of facial lentigines: further epidemiological evidence from Caucasians and Asians. J Invest Dermatol. 2016;136(5):1053-1056.

27. Jimbow K, Park JS, Kato F, et al. Assembly, target-signaling and intracellular transport of tyrosinase gene family proteins in the initial stage of melanosome biogenesis. Pigment Cell Res. 2000;13(4):222-229.
Clinical, Cosmetic and Investigational Dermatology

Publish your work in this journal

Clinical, Cosmetic and Investigational Dermatology is an international, peer-reviewed, open access, online journal that focuses on the latest clinical and experimental research in all aspects of skin disease and cosmetic interventions. This journal is included on PubMed. The manuscript management system is completely online

\section{Dovepress}

and includes a very quick and fair peer-review system, which is all easy to use. Visit http://www.dovepress.com/testimonials.php to read real quotes from published authors 